\title{
Study of the Frequency of Nonalcoholic Fatty Liver Disease (NAFLD) in Type 2 Diabetes Mellitus (DM) in a Tertiary Care Centre
}

\author{
Ipsita B. Malakar ${ }^{1}$, Virendra C. Patil ${ }^{2}$ \\ ${ }^{1}$ Junior Resident, Department of Medicine, Krishna Institute of Medical sciences Deemed to be University, Karad, ${ }^{2}$ Professor \\ and HOD, Department of Medicine, Krishna Institute of Medical sciences Deemed to be University, Karad, Maharashtra, \\ India
}

Corresponding author: Dr. Virendra C. Patil, Professor and HOD, Department of Medicine, KIMS deemed to be University, Karad, Dist: Satara, Maharashtra, India

DOI: http://dx.doi.org/10.21276/ijcmsr.2018.3.4.12

How to cite this article: Ipsita B. Malakar, Virendra C. Patil. Study of the frequency of nonalcoholic fatty liver disease (NAFLD) in type 2 Diabetes Mellitus (DM) in a tertiary care centre. International Journal of Contemporary Medicine Surgery and Radiology. 2018;3(4):D51-D57.

\section{A B S T R A C T}

Introduction: The diabetics are at a higher risk of developing Nonalcoholic fatty liver disease (NAFLD) and its related complications compared to general population at large. Study aimed to evaluate the prevalence of Non-Alcoholic Fatty Liver Disease (NAFLD) and associated demographic, metabolic and biochemical parameters in subjects with type -2 Diabetes Mellitus.

Material and methods: This was a hospital based, prospective, observational, descriptive (cross-sectional) and noninterventional study done on cohort of type 2 diabetes mellitus patients. This study was conducted over period of 18 months (October 2016 to March 2018). Diagnostic criteria for NAFLD: Alcohol consumption <20g/d and USG Abdomen suggestive of fatty liver.

Results: A total 170 patients were enrolled, of them 106 (62.35\%) were males and 64 (37.64\%) were females. There was statistically significant positive correlation between presence of non-alcoholic fatty liver disease and $\mathrm{HbA} 1 \mathrm{c}$ $(+0.25124), \mathrm{BMI}(+0.34743)$ and duration of diabetes (+0.4237). Overall prevalence of NAFLD was 55.29\% (94/170). Male gender, age $>45$ years, $\mathrm{HbA1c}>6.5, \mathrm{BMI}>25 \mathrm{Kg} / \mathrm{M}^{2}$ and duration of diabetes mellitus $>10$ years together were the risk factors associated with presence of NAFLD in present study $(p=0.0002)$.

Conclusion: Present study highlighted the significant burden of Non-Alcoholic Fatty Liver Disease in cohort of type -2 Diabetes Mellitus. About half of the subjects had NAFLD (55.29\%). In present study high BMI, high HbA1c and duration of diabetes $>10$ years were positively correlated with NAFLD.

Key words: Non-Alcoholic Fatty Liver Disease, type 2 Diabetes Mellitus, HbA1c, BMI, Duration of Diabetes Mellitus

\section{INTRODUCTION}

In western and Asian countries, changes in the diet and lifestyle have caused a noteworthy increase in the prevalence of obesity and metabolic syndrome, which has appreciably increased the incidence of non-alcoholic fatty liver disease (NAFLD). The NAFLD comprises of non-alcoholic fatty liver (NAFL) and non-alcoholic steatohepatitis (NASH). The NAFL tends to be benign and non-progressive while the NASH can lead to development of cirrhosis and in rare cases gives rise to hepatocellular carcinoma. NAFLD occurs worldwide, with a prevalence ranging 10-50\%. NAFLD is emerging as an important cause of liver disease in India with prevalence of $9 \%$ to $32 \%$ associated with obesity and Diabetes Mellitus. ${ }^{1,2,3}$ NAFLD is increasingly prevalent in the Indian population, acquaintance regarding its burden and risk factors is limited. NAFLD and type 2 Diabetes Mellitus seems to be a costly and notorious combination of risk factors for various diseases. The NAFLD is commonly linked with type 2 DM despite the fact that its prevalence is not studied well in Indian context. This hospital based crosssectional study was conducted to estimate the frequency and prevalence of NAFLD in subjects with type 2 DM. Study aimed to evaluate the prevalence of Non-Alcoholic Fatty Liver Disease (NAFLD) and associated demographic, metabolic and biochemical parameters in subjects with type -2 Diabetes Mellitus in a tertiary care centre, teaching hospital.

\section{MATERIAL AND METHODS}

This was a hospital based, prospective, observational, descriptive (cross-sectional) and non-interventional study done on cohort of type 2 diabetes mellitus patients.

Settings: This was hospital based study conducted in Krishna Institute of Medical Sciences, Karad, conducted over period 
of 18 months (October 2016 to March 2018). This study was approved by protocol and ethical committee of Krishna Institute of Medical Sciences Deemed to be University, Karad.

Inclusion criteria: All consecutive adult subjects including all genders with type $2 \mathrm{DM}$ fulfilling the inclusion criteria with age more than 18 years were enrolled for this study.

Exclusion criteria: Subjects with a history of alcohol intake more than 30 grams/day in males and more than 20 grams/ day in females or with evidence of acute or chronic viral hepatitis or liver disease ( $\mathrm{HBsAg} / \mathrm{HCV}$ positive, with alcoholic liver disease, autoimmune hepatitis) due to any other cause were excluded from the study. Subjects who were on hepatotoxic medications were also excluded. ${ }^{4,5}$ The subjects diagnosed as Diabetes Mellitus seeking treatment in the Department of Medicine IPD and OPD were included and investigated for presence of NAFLD. After taking informed consent, all subjects underwent history, examination and laboratory investigations (haemoglobin, total leukocyte count and metabolic parameters like blood sugar, glycosylated haemoglobin, liver function test, renal function test and lipid profile) and ultrasonography (USG) of abdomen.

NAFLD-diagnostic criteria: Alcohol consumption <20g/d, USG abdomen suggestive of fatty liver. The USG abdomen for detection of Fatty liver was performed by using B mode Siemens X -300 machine (3.5 - $5 \mathrm{MHz}$ convex probe). ${ }^{6,7}$ Hepatic steatosis if present, was classified based on standard ultrasonographic criteria as:

Grade 1 (mild steatosis): Normal visualization of diaphragm/ intrahepatic vessels.

Grade 2 (moderate steatosis): Impaired visualization of diaphragm/ intrahepatic vessels and
Grade 3 (severe steatosis): Poor visualization of diaphragm/ intrahepatic vessels. ${ }^{6,7}$

\section{STATISTICAL ANALYSIS}

Statistical analysis was done by using the Statistical Package for Social Science (SPSS version 16) trial version. Basic descriptive statistical analysis of the quantitative variables was performed in the form of frequencies, means, percentage, standard deviations, Odds ratio (OR), Relative risk (RR) and chi-square test. The continuous variables were shown as mean \pm standard deviation $(\mathrm{SD})$. The $\mathrm{P}$ values $<0.05$ were considered as significant.

\section{RESULTS}

A total 170 subjects of both genders were enrolled for this

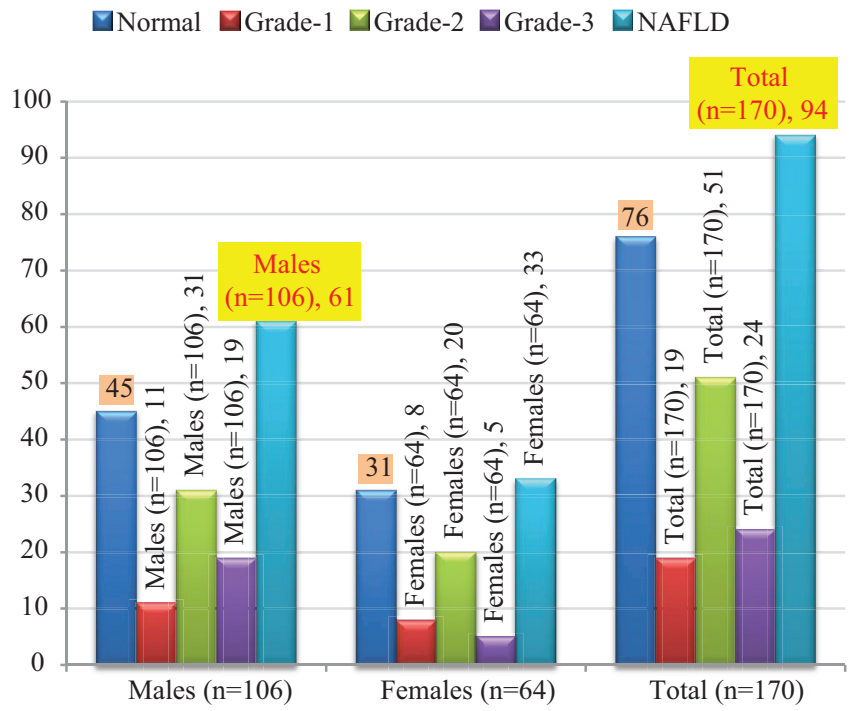

Graph-1: NAFLD in both gender in cohort of type-2 DM

\begin{tabular}{|c|c|c|c|c|c|c|}
\hline Variable & \multicolumn{3}{|c|}{ Total } & \multicolumn{3}{|c|}{$\%$} \\
\hline Males & \multicolumn{3}{|c|}{106} & \multicolumn{3}{|c|}{62.35} \\
\hline Females & \multicolumn{3}{|c|}{64} & \multicolumn{3}{|c|}{37.64} \\
\hline Total & \multicolumn{3}{|c|}{170} & \multicolumn{3}{|c|}{100} \\
\hline \multicolumn{7}{|c|}{$\chi^{2}:$ 20.75; DF:1; $p<0.0001 ;$ Relative Risk(RR): 0.60; Odds Ratio(OR): 0.36} \\
\hline & Normal & Grade-1 & Grade-2 & Grade-3 & NAFLD & $\%$ \\
\hline Males $(n=106)$ & 45 & 11 & 31 & 19 & 61 & 57.54 \\
\hline Females $(n=64)$ & 31 & 8 & 20 & 5 & 33 & 51.56 \\
\hline Total $(n=170)$ & 76 & 19 & 51 & 24 & 94 & 55.29 \\
\hline
\end{tabular}

\begin{tabular}{|c|c|c|c|c|}
\hline Variables & Normal USG $(n=76)$ & Grade-1 fatty liver ( $n=19)$ & Grade-2 fatty liver $(n=51)$ & Grade-3 fatty liver $(n=24)$ \\
\hline Age & $59.15( \pm 13.9)$ & $55.21( \pm 8.29)$ & $59.9( \pm 14.5)$ & $57( \pm 13.83)$ \\
\hline Duration DM & $7.09( \pm 6.99)$ & $11.78( \pm 2.25)$ & $12.6( \pm 3.23)$ & $12.41( \pm 2.14)$ \\
\hline BMI & $26.17( \pm 3.48)$ & $29.66( \pm 3.4)$ & $29.06( \pm 2.79)$ & $28.69( \pm 2.47)$ \\
\hline $\mathrm{BSL}(\mathrm{F})$ & $166.49( \pm 71.94)$ & $180.47( \pm 75.25)$ & $165.68( \pm 55.29)$ & $190.45( \pm 71.82)$ \\
\hline $\mathrm{BSL}(\mathrm{PP})$ & $228.79( \pm 84.64)$ & $226.15( \pm 91.39)$ & $239.17( \pm 58.62)$ & $275.45( \pm 97.95)$ \\
\hline $\mathrm{HbA1c}$ & 7.95( $( \pm 1.47)$ & $7.98( \pm 1.24)$ & $8.36( \pm 1.7)$ & $9.31( \pm 1.8)$ \\
\hline Total CHO & $150.7( \pm 42.95)$ & $153.47( \pm 38.74)$ & $158.88( \pm 35.3)$ & $190.91( \pm 57.49)$ \\
\hline $\mathrm{HDL}$ & $40.08( \pm 17.68)$ & $35.1( \pm 12.35)$ & $41.66( \pm 15.8)$ & $45.2( \pm 14.29)$ \\
\hline Triglyceride & $105.74( \pm 44.54)$ & $159.21( \pm 100.3)$ & $118.58(48.91)$ & $95( \pm 32.85)$ \\
\hline
\end{tabular}




\begin{tabular}{|c|c|c|c|c|}
\hline HbA1c & \multicolumn{2}{|c|}{ Normal USG $(n=76)$} & \multicolumn{2}{|c|}{ NAFLD (n=94) } \\
\hline$\leq 6(n=12)$ & \multicolumn{2}{|c|}{9} & \multicolumn{2}{|c|}{3} \\
\hline$>6(n=158)$ & \multicolumn{2}{|c|}{67} & \multicolumn{2}{|c|}{91} \\
\hline \multicolumn{5}{|c|}{$\chi^{2}$ : 4.793; DF:1; P=0.028; Relative Risk (RR): 2.30; Odds Ratio (OR): 4.07} \\
\hline HbA1c & Normal USG ( $n=76)$ & Grade-1 fatty liver( $n=19)$ & Grade-2 fatty liver $(n=51)$ & Grade-3 fatty liver $(n=24)$ \\
\hline$\leq 6(n=12)$ & 9 & 1 & 2 & 0 \\
\hline$>6(n=158)$ & 67 & 18 & 49 & 24 \\
\hline \multicolumn{5}{|c|}{$\chi^{2}: 5.33177 ; D F: 3 ; P=0.149054$} \\
\hline Gender & Normal USG (n=76) & Grade-1 fatty liver(n=19) & Grade-2 fatty liver $(n=51)$ & Grade-3 fatty liver $(n=24)$ \\
\hline Male(n=106) & $45(42.5 \%)$ & $11(10.37 \%)$ & $31(29.24 \%)$ & $19(17.92 \%)$ \\
\hline Female $(n=64)$ & $31(48.4 \%)$ & $8(12.5 \%)$ & $20(31.25 \%)$ & $5(7.81 \%)$ \\
\hline \multicolumn{5}{|c|}{$\chi^{2}: 3.424395 ; D F: 3 ; p=0.330701$} \\
\hline Gender & \multicolumn{2}{|c|}{ Normal USG $(n=76)$} & \multicolumn{2}{|c|}{ NAFLD $(n=94)$} \\
\hline Male(n=106) & \multicolumn{2}{|c|}{$45(42.45 \%)$} & \multicolumn{2}{|c|}{$61(57.54 \%)$} \\
\hline Female(n=64) & \multicolumn{2}{|c|}{$31(48.4 \%)$} & \multicolumn{2}{|c|}{$33(51.56 \%)$} \\
\hline
\end{tabular}

\begin{tabular}{|c|c|c|c|c|}
\hline BMI & Normal USG ( $n=76)$ & Grade-1 fatty liver(n=19) & Grade-2 fatty liver( $n=51)$ & Grade-3 fatty liver $(n=24)$ \\
\hline$\leq 25(n=40)$ & 33 & 2 & 3 & 2 \\
\hline$>25(n=130)$ & 43 & 17 & 48 & 22 \\
\hline \multicolumn{5}{|c|}{$\chi^{2}: 30.40528 ; \mathrm{DF}: 3 ; \mathrm{P}<0.001$} \\
\hline BMI & \multicolumn{2}{|c|}{ Normal USG $(n=76)$} & \multicolumn{2}{|c|}{$\operatorname{NAFLD}(n=94)$} \\
\hline$\leq 25(n=40)$ & \multicolumn{2}{|c|}{33} & \multicolumn{2}{|c|}{7} \\
\hline$>25(n=130)$ & \multicolumn{2}{|c|}{43} & \multicolumn{2}{|c|}{87} \\
\hline \multicolumn{5}{|c|}{$\chi^{2}: 3.57 ; \mathrm{DF}: 1 ; p=0.058$; Relative Risk (RR): 0.26; Odds Ratio (OR): 0.10} \\
\hline Duration of DM & Normal USG (n=76) & Grade-1 fatty liver( $n=19)$ & Grade- 2 fatty liver $(n=51)$ & Grade-3 fatty liver( $n=24)$ \\
\hline$\leq 10$ yrs $(n=84)$ & 64 & 5 & 11 & 4 \\
\hline$>10(n=86)$ & 12 & 14 & 40 & 20 \\
\hline \multicolumn{5}{|l|}{$\mathrm{p}<0.001$} \\
\hline Duration of DM & \multicolumn{2}{|c|}{ Normal USG ( $n=76)$} & \multicolumn{2}{|c|}{ NAFLD (n=94) } \\
\hline$\leq 10$ yrs $(n=84)$ & \multicolumn{2}{|c|}{64} & \multicolumn{2}{|c|}{20} \\
\hline$>10$ yrs $(n=86)$ & \multicolumn{2}{|c|}{12} & \multicolumn{2}{|c|}{74} \\
\hline \multicolumn{5}{|c|}{$\chi^{2}:$ 66.586; DF:1; $p<0.001 ;$ Relative Risk (RR): 0.27; Odds Ratio (OR): 0.05} \\
\hline Age & \multicolumn{2}{|c|}{ Normal USG $(n=76)$} & \multicolumn{2}{|c|}{ NAFLD (n=94) } \\
\hline$\leq 45$ yrs $(n=33)$ & \multicolumn{2}{|c|}{15} & \multicolumn{2}{|c|}{18} \\
\hline$>45$ yrs $(n=137)$ & \multicolumn{2}{|c|}{71} & \multicolumn{2}{|c|}{76} \\
\hline \multicolumn{5}{|c|}{$\chi^{2}$ : 4.26; DF:1; $p=0.038 ;$ Relative Risk (RR): 0.98; Odds Ratio (OR): 0.96} \\
\hline
\end{tabular}

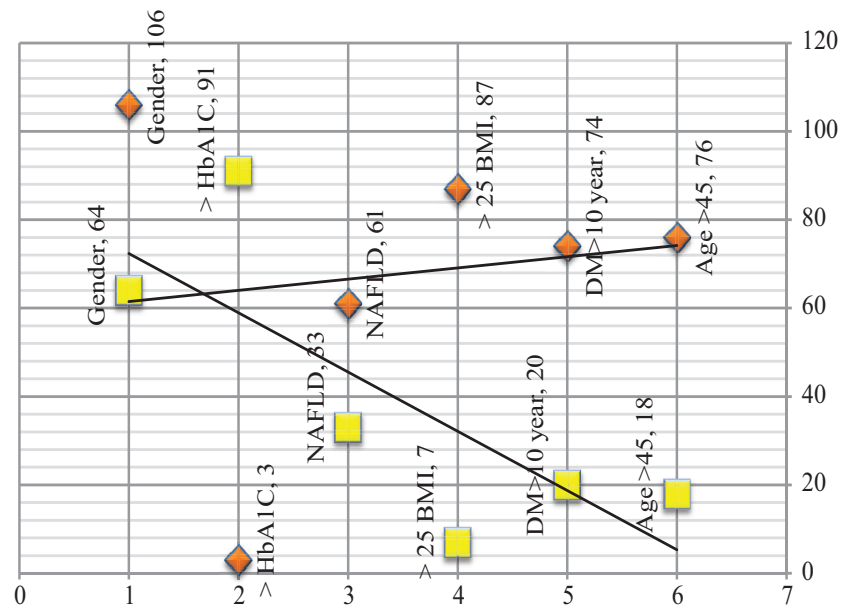

Graph-2: Relation of NAFLD with risk factors cross-sectional observational study as per inclusion criteria. Total 106 (62.35\%) were males and 64 (37.64\%) were females [p $<0.0001]$. Present study predominated by male subjects (62.35\%) compared to female subjects (37.64\%). Overall prevalence of NAFLD was $55.29 \%$ (94/170). The prevalence of NAFLD was $57.54 \%(61 / 106)$ and $51.56 \%(33 / 64)$ in males and females respectively. (Table 1 and Graph 1)

The mean of age, HbA1c and total cholesterol was relatively high in subjects with NAFLD compared to subjects without NAFLD. (Table 2)

The HbA1c >6 had statistically significant association with presence of NAFLD in present study $[(\mathrm{p}=0.028569)$ (Odds Ratio (OR) 4.074627)]. The severity and grades of NAFLD was not significantly associated with HbA1c $>6(p=0.149054)$. The severity and grades of NAFLD was not significant among genders $(\mathrm{p}=0.330701)$. The presence 
of NAFLD was not significantly associated with gender $(\mathrm{p}=0.447021)$. (Table 3$)$

\begin{tabular}{|c|c|c|}
\hline \multicolumn{2}{|l|}{ Variables } & Correlation $=r$ \\
\hline \multicolumn{2}{|l|}{ HbA1c } & +0.25124 \\
\hline \multicolumn{2}{|l|}{ BMI } & +0.34743 \\
\hline \multicolumn{2}{|l|}{$\mathrm{BSL}(\mathrm{F})$} & +0.0767 \\
\hline \multicolumn{2}{|l|}{$\mathrm{BSL}(\mathrm{PP})$} & +0.16249 \\
\hline \multicolumn{2}{|l|}{ HDL level } & +0.09981 \\
\hline \multicolumn{2}{|l|}{ SGOT/AST } & +0.14338 \\
\hline \multicolumn{2}{|l|}{ SGPT/ALT } & +0.06392 \\
\hline \multicolumn{2}{|c|}{ Duration of diabetes } & +0.4237 \\
\hline \multicolumn{2}{|c|}{ Triglyceride } & -0.0048 \\
\hline \multicolumn{2}{|l|}{ Age } & -0.0205 \\
\hline \multicolumn{2}{|l|}{ SBP } & -0.052 \\
\hline \multicolumn{2}{|l|}{ DBP } & -0.0283 \\
\hline \multicolumn{2}{|l|}{ Bilirubin } & -0.0431 \\
\hline \multicolumn{2}{|l|}{ Weight } & -0.1596 \\
\hline Gender & Males $(n=106)$ & Females $(n=64)$ \\
\hline$>\mathrm{HbA} 1 \mathrm{c}$ & 91 & 3 \\
\hline$>25 \mathrm{BMI}$ & 87 & 7 \\
\hline $\mathrm{DM}>10$ year & 74 & 20 \\
\hline Age $>45$ & 76 & 18 \\
\hline \multicolumn{3}{|c|}{$\chi^{2}: 19.6789 ; D F: 3 ; p=0.0002$} \\
\hline \multicolumn{3}{|c|}{$\begin{array}{l}\text { Table-5: Correlation of various demographic, clinical and labo- } \\
\text { ratory parameters with NAFLD in cohort of type-2 DM subjects }\end{array}$} \\
\hline
\end{tabular}

The severity and grades of NAFLD was statistically significantly associated with $\mathrm{BMI}>25 \mathrm{Kg} / \mathrm{M}^{2}(\mathrm{p}<0.001)$. The NAFLD was significantly associated with $\mathrm{BMI}>25$ $\mathrm{Kg} / \mathrm{M}^{2}$ ( $\mathrm{p}=0.05866$ ). The severity and grades of NAFLD was statistically significantly associated with duration of diabetes $(\mathrm{p}<0.001)$. The presence of NAFLD was statistically significantly associated with duration ( $>10$ years) of diabetes $(p<0.001)$. The severity and grades of NAFLD was not statistically significantly associated with age $(\mathrm{p}=0.9631406)$. The presence of NAFLD was statistically significantly associated with age $>45$ years $(p=0.03886854)$. (Table 4)

The severity and grades of NAFLD was not statistically significantly associated with high total cholesterol $(p=0.07340511)$. The NAFLD was not statistically significantly associated with total cholesterol $>150 \mathrm{mg}$ $(\mathrm{p}=0.63183404)$. The severity and grades of NAFLD was not statistically significantly associated with serum triglyceride level $>150 \mathrm{mg}$ ( $\mathrm{p}=0.06245557)$. The presence of NAFLD was statistically significantly associated with triglyceride $>150$ $\mathrm{mg}(\mathrm{p}=0.03498023)$. [Odds Ratio (OR): 0.511509; Relative Risk (RR): 0.748353] The severity and grades of NAFLD was not statistically significantly associated with serum HDL $<50 \mathrm{mg}$ ( $\mathrm{p}=0.16467667)$. The presence of NAFLD was not statistically significantly associated with decreasing serum HDL < $50 \mathrm{mg}[(\mathrm{p}=0.21717278)$ Odds Ratio (OR): 1.883117; Relative Risk (RR): 1.380952].

\begin{tabular}{|c|c|c|c|}
\hline Author & Total (n) & Prevalence/Incidence & Associated factors with NAFLD \\
\hline Majumdar A et al & 176 & $30.70 \%$ & Central obesity \\
\hline Bhatt $\mathrm{KN}$ et al & 100 & 45 & BMI, higher HbA1c, higher triglyceride \\
\hline Jaseem Ansari et al & 100 & $26 \%$ & Hypertension, obesity, duration of Diabetes Mellitus \\
\hline Lavekar A et al & 302 & $28.10 \%$ & Metabolic syndrome and Diabetes Mellitus \\
\hline Prabhakar A et al & 114 & $41.20 \%$ & HbA1c, duration of diabetes and obesity \\
\hline Gupta M et al & 150 & $69.33 \%$ & DM, older age and increasing BMI \\
\hline Bhardwaj et al & 100 & $61 \%$ & HTN, MeTS and raised cholesterol, LDL triglycerides \\
\hline Chandel $\mathrm{K}$ et al & 185:105 & $55.68 \% / 20 \%$ & High BMI, HbA1c, triglyceride, hypercholesterolemia, low HDL \\
\hline Younossi ZM et al & - & $9-40 \%$ & Asian countries \\
\hline & - & $15-40 \%$ & Western countries \\
\hline & - & $9-32 \%$ & In India \\
\hline & - & $12.5-87.5 \%$ & In cohort of type 2 Diabetes Mellitus \\
\hline Sung K-C et al & 51,418 & $12 \%$ & Incidence of NAFLD by USG \\
\hline Tsuneto A et al & 635 & $19.9 / 1,000$ person-yr & Incidence of NAFLD by ultrasound \\
\hline Wong VW et al & 565 & $13.5 \%(34 / 1,000 \mathrm{yrs})$ & Incidence by MRI and transient elastography (TE) \\
\hline Chang Y et al & 77425 & $29.7 / 1000$ & incidence rate 29.7 per 1,000 person yrs \\
\hline Whalley S et al & - & $29 / 1000$ & 29 per 100,000 person-years \\
\hline Zelber S et al & - & $28 / 1000$ & 28 per 1,000 person-years \\
\hline Younossi ZM et al & Meta-analysis & $52.34 ; 28$ & Asia: 52.34; West:28 per 1,000 \\
\hline Vernon $\mathrm{G}$ et al & - & $7 \%-46 \%$ & - \\
\hline Williams CD et al & 400 & $46 \%$ & Histologically confirmed NASH (12.2\%) \\
\hline Browning JD et al & - & $31 \%$ & Dallas Heart Study by MR spectroscopy \\
\hline Younossi ZM et al & \multicolumn{3}{|c|}{$\begin{array}{l}\text { The meta-analysis estimated prevalence of NAFLD by imaging was around } 25.24 \% \text {, Middle East ( } 31.79 \%) \text {, } \\
\text { South America ( } 30.45 \%) \text { and Africa ( } 13.48 \% \text { ). The prevalence of NASH among NAFLD subjects by liver biopsy } \\
\text { was } 59.10 \% \text { and by liver biopsy was } 6.67 \% \text { to } 29.85 \% \text {. }\end{array}$} \\
\hline Present study & \multicolumn{3}{|c|}{$\begin{array}{l}\text { Of total } 170 \text { subjects, } 106(62.35 \%) \text { were males and } 64(37.64 \%) \text { were females }(p<0.0001) \text {. Preva- } \\
\text { lence of NAFLD was } 55.29 \%(94 / 170) \text {. The presence of NAFLD was significantly associated with BMI }>25 \mathrm{Kg} / \\
\mathrm{M}^{2}(p<0.001) \text {, duration }(>10 \text { years }) \text { of diabetes }(p<0.001) \text { and age }>45 \text { years }(p=0.038) \text {. }\end{array}$} \\
\hline \multicolumn{4}{|c|}{ Table-6: Comparison of various studies prevalence with present study ${ }^{10-28}$} \\
\hline
\end{tabular}


Correlation coefficient: There was statistically significant positive correlation between different grades of non-alcoholic fatty liver and $\mathrm{HbA1c}(+0.25124)$, BMI $(+0.34743)$, BSL (F) (+0.0767), BSL (PP) (+0.16249), serum HDL level $(+0.09981), \quad$ SGOT/AST level $(+0.14338)$, SGPT/ALT $(+0.06392)$ and duration of diabetes $(+0.4237)$. There was significant negative correlation between different grades of non-alcoholic fatty liver and serum triglyceride $(-0.0048)$, age $(-0.0205)$, systolic blood pressure $(-0.052)$, diastolic blood pressure (-0.0283), total bilirubin level (-0.0431) and weight (-0.1596). (Table 5) In multivariate analysis after controlling age and gender there was statistically significant association between NAFLD (grade 2 fatty liver) and BMI, duration of Diabetes Mellitus and HbA1c $(\mathrm{p}<0.01)$. Male gender, age $>45, \mathrm{HbA} 1 \mathrm{c}>6.5, \mathrm{BMI}>25 \mathrm{Kg} / \mathrm{M}^{2}$, duration of Diabetes Mellitus > 10 years together were as a risk factors associated significantly with presence of NAFLD in present study ( $\mathrm{p}=0.0002)$. (Table 5 and graph 2$)$

\section{DISCUSSION}

Non-alcoholic fatty liver disease (NAFLD) was a distinct hepatic condition that was strongly associated with insulin resistance and type 2 Diabetes Mellitus. NAFLD has become an important health issue globally. The NAFLD is increasingly seen to be associated with metabolic syndrome. There are limited number of studies on epidemiology and natural history of NAFLD in diabetes. In the present cross-sectional observational study a total 170 subjects of both genders were enrolled of them 106 (62.35\%) were males and 64 (37.64\%) were females $(p<0.0001)$. The HbA1c $>6$ had statistically significant association with presence of NAFLD in present study $(\mathrm{p}=0.028)$. Overall prevalence of NAFLD was $55.29 \%$ (94/170). The prevalence of NAFLD was $57.54 \%(61 / 106)$ and $51.56 \%(33 / 64)$ in males and female respectively. The NAFLD was statistically significantly associated with BMI $>25 \mathrm{Kg} / \mathrm{M}^{2}(\mathrm{p}=0.058)$. The severity and grades of NAFLD was statistically significantly associated with $\mathrm{BMI}>25 \mathrm{Kg} /$ $\mathrm{M}^{2}(\mathrm{p}<0.001)$, duration of Diabetes Mellitus ( $>10$ years) $(\mathrm{p}<0.001)$, age $>45$ years $(\mathrm{p}=0.038)$ and triglyceride $>150 \mathrm{mg}$ $(\mathrm{p}=0.034)$. Present study cannot be exactly compared with other studies from India and overseas because of different criterion for enrolment of subject for study, difference of criteria for diagnosing NAFLD, community based, different geographic area and genetic makeup of study population. Chen $\mathrm{CH}$ et al in their cross-sectional community based study of 3245 adults of Taiwan quoted prevalence of NAFLD of $11.5 \%$. NAFLD was closely associated with obesity and Diabetes Mellitus. This prevalence is relatively low compared to present study [55.29\% (94/170)] as it was hospital based study included only subjects with type $2 \mathrm{DM}$. The other parameters like obesity $(\mathrm{BMI})(\mathrm{p}<0.001)$ and hypertriglyceridemia $(\mathrm{p}=0.034)$ are comparable with present study. ${ }^{8}$ Younossi ZM et al quoted prevalence of NAFLD in Asian countries varies from $9-40 \%$ and in western countries from $15-40 \%$. In India, the prevalence of NAFLD was around $9-32 \%$ in the general population, but it was $12.5-$ $87.5 \%$ in subjects with type $2 \mathrm{DM}^{9}{ }^{9}$ These findings are comparable with present study (55.29\%). Majumdar A et al (2016) studied 176 participants with prevalence of NAFLD was $30.7 \%$ and was associated with central obesity. In current study the prevalence of NAFLD was quite high (55.29\%) may be due to only cohort of type-2 DM were included. Association of BMI with NAFLD in present study was significant, similar to study by Majumdar A et al. ${ }^{10}$ Bhatt KN et al (2017) in their study of total 100 subjects of type 2 DM the prevalence of NAFLD was $45 \%$ with obesity (measured by BMI), higher $\mathrm{HbA1c}$, higher triglyceride levels had significant association with NAFLD. ${ }^{11}$ These findings are comparable with present study with prevalence of NAFLD of $55.29 \%$ and association of BMI, TRG, HbA1c was enough significant with NAFLD. Compared to present study (55.29\%), Jaseem Ansari et al (2017) found 26\% prevalence of NAFLD which was significantly low, could be due to different inclusion and exclusion criteria. ${ }^{12}$ Lavekar A et al (2015) studied 302 individuals with prevalence of NAFLD of $28.1 \%$, which was relatively low compared to our study as we have enrolled only type $-2 \mathrm{DM}$ subjects which is one of the proved risk factor for NAFLD. ${ }^{13}$ Prabhakar A et al (2017) quoted prevalence of NAFLD was $41.2 \%$ in the study group $(n=114)$, which is similar to present study. Prevalence of NAFLD was significantly associated with $\mathrm{HbA1}$, duration of diabetes and obesity, these findings are comparable with our study. ${ }^{14}$ Gupta $\mathrm{M}$ et al (2017) in their hospital based observational descriptive study $(\mathrm{n}=150)$ in subjects with T2DM, 104 (69.33\%) had fatty liver on USG, $42.67 \%$ had grade $1,24 \%$ had grade 2 , and the remaining $2.67 \%$ had grade 3 fatty changes in liver. ${ }^{15}$ These findings are comparable with present study with overall prevalence of NAFLD of $55.29 \%$ (94/170). The NAFLD was statistically significantly associated with $\mathrm{BMI}>25 \mathrm{Kg} / \mathrm{M}^{2}(\mathrm{p}<0.001)$, duration ( $>10$ years) of Diabetes Mellitus $(\mathrm{p}<0.001)$, age $>45$ years $(\mathrm{p}=0.038)$ and triglyceride $>150 \mathrm{mg}(\mathrm{p}=0.034)$. Bhardwaj et al (2016) in their cross-sectional study $(\mathrm{n}=100)$ with subjects of type 2 diabetes, the prevalence of NAFLD was $61 \% .{ }^{16}$ These findings are similar to present study with prevalence of NAFLD of $55.29 \%$ (94/170). The NAFLD was statistically significantly associated with BMI > 25 $\mathrm{Kg} / \mathrm{M}^{2}$, duration ( $>10$ years) of diabetes, age $>45$ years and triglyceride $>150 \mathrm{mg}$. Similarly Chandel K et al (2016) in their study of total of 185 diabetic and 105 non-diabetic subjects quoted prevalence of NAFLD in DM was $55.68 \%$ and in non-diabetic was $20 \% .{ }^{17}$ There is a paucity of data regarding the incidence of NAFLD in the general population. We compared the prevalence and risk factors of NAFLD in the general population with present study. (Table 6)

Limitations of the study: This was a hospital based study and conducted only on cohort of type-2 Diabetes Mellitus subjects. The present study lacks histological evidence for NAFLD and improved imaging modality like MRI spectroscopy.

\section{CONCLUSION}

Present study highlighted the significant Non-Alcoholic Fatty Liver Disease burden in cohort of type-2 Diabetes Mellitus; about half of the subjects had NAFLD (55.29\%). NAFLD and type $2 \mathrm{DM}$ seems to be a costly combination of risk factors for various diseases. In present study high BMI, 
high $\mathrm{HbA} 1 \mathrm{c}$ and duration of diabetes > 10 years and age > 45 years were positively correlated with presence NAFLD. Physicians must have awareness about the complications associated with NAFLD. Lifestyle modification, remain the corner stone in management of NAFLD. Subjects with type 2 DM should always be assessed for NAFLD to ensure early diagnosis which might help in modifying the disease course and delaying its complications. Thus, subjects with Diabetes mellitus must be evaluated for the presence of NAFLD by inexpensive and non-invasive examination like abdominal Ultrasonography.

\section{REFERENCES}

1. Angulo P. Nonalcoholic fatty liver disease. N Engl J Med.2002;346(1):1221- 1231.

2. Harrison SA, Neuschwander-Tetri BA: Nonalcoholic fatty liver disease and nonalcoholic steatohepatitis. Clin Liver Dis. 2004;8 (4):861-879.

3. Etsuko Hashimoto, Katsutoshi Tokushige and Jurgen Ludwig. Diagnosis and classification of non-alcoholic fatty liver disease and non-alcoholic steatohepatitis: Current concepts and remaining challenges. The Japan Society of Hepatology. Hepatology Research. 2014. 1-9.

4. Schaffner F. Non-alcoholic fatty liver. In: Berk JE, Haubrich WS, Kalser MH, eds. Bockus Gastroenterology, 4 edn. Philadelphia, PA: Saunders, 1985; 3049-61.

5. Chalasani N, Zobair Younossi, Joel E. Lavine, Michael Charlton, Kenneth Cusi, Mary Rinella et al. The diagnosis and management of nonalcoholic fatty liver disease: Practice guidance from the American Association for the Study of Liver Diseases. Hepatology. 2018; 67(1):329-357.

6. Hamer OW, Aguirre DA, Casola G, Lavine JE, Woenckhaus M, Sirlin CB. Fatty liver imaging and pitfalls. Radiographics. 2006;26 (3):1637-53.

7. Gore RM. Diffuse liver disease. In: Gore RM, Levine MS, Laufer I (Eds). Textbook of Gastrointestinal Radiology. Philadelphia: WB Saunders; 1994:19682017.

8. Chen $\mathrm{CH}$, Huang $\mathrm{MH}$, Yang JC, Nien CK, Yang $\mathrm{CC}$, Yeh YH et al. Prevalence and risk factors of nonalcoholic fatty liver disease in an adult population of Taiwan: metabolic significance of non-alcoholic fatty liver disease in nonobese adults. J Clin Gastroenterol. 2006;40 (5):745-752.

9. Yang K. C. et al. Association of Non-alcoholic Fatty Liver Disease with Metabolic Syndrome Independently of Central Obesity and Insulin Resistance. Sci. Rep. 2016;6(27034);1-9.

10. Majumdar A, Misra P, Sharma S, Kant S, Krishnan A, Pandav CS. Prevalence of nonalcoholic fatty liver disease in an adult population in a rural community of Haryana, India. Indian J Public Health. 2016;60 (1):26-33.

11. Bhatt KN, Pranav V, Dipika Y, Dharmesh N, Radhika $\mathrm{N}$, Arvind S. Prevalence of nonalcoholic fatty liver disease in type 2 diabetes mellitus and its relation with insulin resistance in South Gujarat region. J Mahatma Gandhi Inst Med Sci. 2017;22 (4):8-11.

12. Jaseem Ansari, Roshan M. Study on Non Alcoholic Fatty Liver Diseases in Type 2 Diabetes Mellitus with
Clinical Correlation. IOSR Journal of Dental and Medical Sciences (IOSR-JDMS). 2017;16(1):100-118.

13. Lavekar Anurag, Saoji Aniket, Jadhav Shalik, Lavekar Amarja, Raje Dhananjay, Jibhkate Sachin. Nonalcoholic fatty liver disease prevalence and associated risk factors - A study from rural sector of Maharashtra. Tropical Gastroenterology. 2015;36(1):25-30.

14. Prabhakar A, Ambili NR, Kartha TDU, Renymol B. Prevalence of non-alcoholic fatty liver disease (NAFLD) in patients with type 2 diabetes mellitus and its correlation with coronary artery disease (CAD). Int J Res Med Sci. 2017;5 (2):5175-81.

15. Gupta M, Mahavar S, Chaturvedi A, Chandra R, Chauhan G, Srivastava S, Sharma R. Magnitude of nonalcoholic fatty liver disease (NAFLD) and concomitant risk factors in patients with type 2 diabetes mellitus. Int J Adv Med. 2017;4 (3):1046-52.

16. Raminderpal Singh Sibia, Sandeep Dhoot, Preetkanwal Sibia, Sourabh Murarka, Harnoor Bhardwaj, Akash Deep Aggarwal. Prevalence of Non-Alcoholic Fatty Liver Disease in Patients with Type 2 Diabetes and its Correlation with Coronary Risk Factors National Journal of Laboratory Medicine. 2016;5(4): IO11IO13.

17. Chandel K, Sandeep Kumar, Waseem Farooqui, Mahak Lamba. A study of prevalence of non-alcoholic fatty liver disease in type 2 Diabetes Mellitus. Panacea Journal of Medical Sciences, September-December. 2016;6(3): 147-150.

18. Younossi ZM, Gramlich T, Matteoni CA, et al. Nonalcoholic fatty liver disease in patients with type 2 diabetes. Clin Gastroenterol Hepatol. 2004;2 (6):262-5.

19. Sung K-C, Wild SH, Byrne CD. Development of new fatty liver, or resolution of existing fatty liver, over five years of follow-up, and risk of incident hypertension. J Hepatol. 2014;60 (5):1040-1045.

20. Tsuneto A, Hida A, Sera N, Imaizumi M, Ichimaru S, Nakashima E, et al. Fatty liver incidence and predictive variables. Hypertens Res. 2010;33 (6):638-643.

21. Wong VW, Wong GL, Yeung DK, Lau TK, Chan CK, Chim AM, et al. Incidence of non-alcoholic fatty liver disease in Hong Kong: a population study with paired proton-magnetic resonance spectroscopy. J Hepatol. 2015;62 (4):182-189.

22. Chang Y, Jung HS, Cho J, Zhang Y, Yun KE, Lazo M et al. Metabolically healthy obesity and the development of non-alcoholic fatty liver disease. Am J Gastroenterol. 2016;111 (3):1133-1140.

23. Whalley S, Puvanachandra P, Desai A, Kennedy H. Hepatology outpatient service provision in secondary care: a study of liver disease incidence and resource costs. Clin Med. 2007;7 (1):119-124.

24. Zelber-Sagi S, Lotan R, Shlomai A, Webb M, Harrari $\mathrm{G}$, Buch A, et al. Predictors for incidence and remission of NAFLD in the general population during a sevenyear prospective follow-up.J Hepatol.2012;56 (8):11451151.

25. Younossi ZM, Koenig AB, Abdelatif D, Fazel Y, Henry L, Wymer M. Global epidemiology of nonalcoholic fatty liver disease-Meta-analytic assessment of prevalence, incidence, and outcomes. Hepatology. 2016;64 (1):73- 
84.

26. Vernon G,Baranova A, Younossi ZM. Systematic review: the epidemiology and natural history of non-alcoholic fatty liver disease and non-alcoholic steatohepatitis in adults. Aliment Pharmacol Ther. 2011;34 (3): 274-285.

27. Williams CD, Stenger J, Asike MI, Torres DM, Shaw J, Contreras M, Landt CL, Harrwason SA. Prevalence of nonalcoholic fatty liver disease and nonalcoholic steatohepatitis among a largely middle-aged population utilizing ultrasound and liver biopsy: a prospective study. Gastroenterology. 2011;140 (5):124-131.

28. Browning JD, Szczepaniak LS, Dobbins R, Nuremberg P, Horton JD, Cohen JC, Grundy SM, Hobbs HH. Prevalence of hepatic steatosis in an urban population in the United States: impact of ethnicity. Hepatology. 2004;40 (4):1387-95.

Source of Support: Nil; Conflict of Interest: None

Submitted: 08-10-2018; Accepted: 06-11-2018; Published online: 17-11-2018 